\title{
Hubungan antara Ketercapaian dan Keterkontrolan Sistem Diskrit Linier
}

\author{
ERISTIA ARFI \\ Program Studi Matematika, \\ Fakultas Matematika dan Ilmu Pengetahuan Alam, Universitas Andalas Padang, \\ Kampus UNAND Limau Manis Padang 25163, Indonesia \\ eri5.poenya@gmail.com
}

\begin{abstract}
Abstrak. Tulisan ini membicarakan hubungan antara ketercapaian dan keterkontrolan sistem linier diskrit linier. HUbungan ini dijelaskan dengan kaidah-kaidah aljabar linier. Hasil akhir menunjukkan sistem tercapai jika dan hanya jika sistem terkontrol.

Kata kunci: Sistem linier diskrit, ketercapaian, keterkontrolan.
\end{abstract}

\section{Pendahuluan}

Diberikan suatu sistem linier diskrit berikut:

$$
\mathbf{x}(k+1)=A \mathbf{x}(k)+B \mathbf{u}(k), \quad \mathbf{x}\left(k_{0}\right)=\mathbf{x}_{0},
$$

dengan $A \in \mathbb{R}^{n \times n}, B \in \mathbb{R}^{n \times m}$ dan $k \in \mathbb{Z}_{+}$. Notasi $\mathbb{R}^{n}$ menyatakan himpunan vektor-vektor riil yang terdiri atas $n$ komponen dan $\mathbb{R}^{n \times m}$ menyatakan himpunan matriks-matriks riil berukuran $n \times m$. Pada sistem (1), $\mathbf{x} \in \mathbb{R}^{n}$ menyatakan vektor keadaan (state) dan $\mathbf{u} \in \mathbb{R}^{m}$ menyatakan vektor kontrol (input).

Dalam [2] dinyatakan bahwa solusi dari sistem (1) adalah

$$
\mathbf{x}(k)=\Phi\left(k, k_{0}\right) \mathbf{x}\left(k_{0}\right)+\sum_{i=k_{0}}^{k-1} \Phi(k, i+1) B \mathbf{u}(i),
$$

dimana

$$
\Phi\left(k, k_{0}\right)=A^{k-k_{0}} .
$$

Salah satu isu utama dalam kontrol diskrit adalah masalah ketercapaian dan keterkontrolan. Suatu keadaan $\mathbf{x}_{1}$ untuk sistem (1) dikatakan tercapai jika terdapat suatu input $\mathbf{u}$ yang mentransfer keadaan $\mathbf{x}_{0}=\mathbf{0}$ kepada keadaan $\mathbf{x}_{1}$ dalam waktu yang berhingga $k$. Sistem (1) dikatakan tercapai jika setiap keadaan dari sistem tersebut tercapai.

Selanjutnya, suatu keadaan $\mathbf{x}_{0}$ dikatakan terkontrol apabila terdapat suatu input $\mathbf{u}$ yang mentransfer keadaan $\mathbf{x}_{0}$ kepada keadaan $\mathbf{x}_{1}=\mathbf{0}$ dalam suatu waktu hingga $k$. Sistem (1) dikatakan terkontrol jika setiap keadaan dari sistem tersebut adalah terkontrol. Untuk matriks $A$ dan $B$ yang berukuran relatif besar, penggunaan definisi-definisi di atas untuk menentukan keterkontrolan dan ketercapaian dari sistem diskrit (1) tidaklah sederhana. Dalam kasus itu, diperlukan kriteria uji untuk ketercapaiaan dan keterkontrolan sistem (1). Dalam [2], beberapa kriteria uji yang dimaksud sudah tersedia. Makalah ini mengkaji hubungan antara ketercapaian dan keterkontrolan sistem diskrit linier.

Dalam paper ini akan dibahas kembali hubungan antara ketercapaian dan keterkontrolan pada sistem (1). 


\section{Ketercapaian Sistem Linier Diskrit}

Diberikan sistem (1) yang merupakan sistem linier diskrit bebas waktu

$$
\mathbf{x}(k+1)=A \mathbf{x}(k)+B \mathbf{u}(k), \quad k \geq k_{0},
$$

dengan $A \in \mathbb{R}^{n \times n}, B \in \mathbb{R}^{n \times m}$. Keadaan $\mathbf{x}(k)$ yang merupakan solusi dari (1) dapat ditentukan sebagai berikut:

$$
\mathbf{x}(k)=\Phi\left(k, k_{0}\right) \mathbf{x}\left(k_{0}\right)+\sum_{i=k_{0}}^{k-1} \Phi(k, i+1) B \mathbf{u}(i),
$$

dimana

$$
\Phi\left(k, k_{0}\right)=A^{k-k_{0}} .
$$

Misalkan $\mathbf{x}\left(k_{0}\right)=\mathbf{x}_{0}$, asumsikan terdapat input $\mathbf{u}$ yang membawa keadaan $\mathbf{x}_{0}$ kepada keadaan $\mathbf{x}\left(k_{1}\right)=\mathbf{x}_{1}$ pada waktu $k_{1}>k_{0}$. Bila $k_{0}=0, k_{1}=K$ dan $\Phi\left(k_{1}, k_{0}\right)=A^{K}$, maka persamaan (2) dapat ditulis kembali

$$
\mathbf{x}_{1}=A^{K} \mathbf{x}_{0}+\sum_{i=0}^{K-1} A^{K-(i+1)} B \mathbf{u}(i),
$$

ketika $K>0$, atau

$$
\mathbf{x}_{1}=A^{K} \mathbf{x}_{0}+\mathcal{C}_{K} U_{K}
$$

dimana

$$
\mathcal{C}_{K} \triangleq\left[B, A B, \ldots, A^{K-1} B\right]
$$

dan

$$
U_{K} \triangleq[u(K-1), u(K-2), \ldots, u(0)]^{T} .
$$

Definisi 1. [2] Suatu keadaan $\mathbf{x}_{1}$ dikatakan tercapai jika terdapat input $\mathbf{u}(k)$, $k \in \mathbb{Z}_{+}$, yang mentransfer keadaan $\mathbf{x}(k)$ dalam sistem (1.1.1) dari keadaan $\mathbf{x}(0)=\mathbf{0}$ kepada keadaan $\mathbf{x}_{1}$ dalam waktu berhingga $K$, yaitu $\mathbf{x}_{1}=\mathbf{x}(K)$.

Sehingga bila $\mathbf{x}_{1}$ tercapai, maka

$$
\mathbf{x}(K)=\mathbf{x}_{1}=\sum_{i=0}^{K-1} A^{K-(i+1)} B \mathbf{u}(i) .
$$

Misalkan $\mathfrak{R}_{r}$ menyatakan himpunan keadaan tercapai dalam waktu $K$, secara simbolik dapat ditulis

$$
\mathfrak{R}_{r}=\left\{\mathbf{x} \in \mathbb{R}^{n} \mid \mathbf{x} \text { tercapai dalam waktu } K\right\} .
$$

Definisi 2. [2] Sistem (1) dikatakan tercapai jika setiap keadaan $\mathbf{x} \in \mathbb{R}^{n}$ adalah tercapain dalam $K$ langkah.

Teorema 1. (i) Terdapat input $\mathbf{u}$ yang mentransfer keadaan $\mathbf{x}(0)=\mathbf{0}$ kepada keadaan $\mathbf{x}_{1}$ dalam waktu berhingga $K$ jika dan hanya jika

$$
\mathbf{x}_{1} \in \mathcal{R}(\mathcal{C})
$$

(ii) $\mathfrak{R}_{r}=\mathcal{R}(\mathcal{C})$. 
(iii) Input $U_{n} \triangleq[u(n-1), u(n-2), \ldots, u(0)]^{T}$ mentransfer keadaan $\mathbf{x}(0)=\mathbf{0}$ kepada keadaan $\mathbf{x}_{1}$ dalam $n$ langkah.

Akibat 1. [2] Sistem (1) tercapai jika dan hanya jika

$$
\operatorname{rank} \mathcal{C}=n
$$

Bukti. Sistem (1) tercapai, akan ditunjukkan $\operatorname{rank} \mathcal{C}=n$. Berdasarkan Teorema 2.1, bila sistem tercapai maka $\mathcal{R}(\mathcal{C})=\mathfrak{R}_{r}$. Selain itu, dari definisi ketercapaian, $\mathfrak{R}_{r}=\mathbb{R}^{n}$. Sehingga, bila sistem (1) tercapai maka

$$
\mathcal{R}(\mathcal{C})=\mathfrak{R}_{r}=\mathbb{R}^{n} .
$$

Hubungan (8) memperlihatkan bahwa dimensi dari $\mathcal{R}(\mathcal{C})$ adalah $n$ atau rank $\mathcal{C}=$ $n$.

Bila rank $\mathcal{C}=n$, maka $\mathcal{R}(\mathcal{C})=\mathbb{R}^{n}$. Akan ditunjukkan bahwa sistem (1) tercapai. Keadaan $\mathbf{x}_{1} \in \mathcal{R}(\mathcal{C})$, karena $\mathcal{R}(\mathcal{C})=\mathbb{R}^{n}$ maka $\mathbf{x}_{1} \in \mathbb{R}^{n}$. Berdasarkan Teorema 2.1, terdapat input $U_{n}$ yang mentransfer keadaan $\mathbf{0}$ kepada keadaan $\mathbf{x}_{1}$. Oleh karena itu sistem (1) merupakan sistem yang tercapai.

\section{$3 \quad$ Keterkontrolan Sistem Linier Diskrit}

Definisi 3. [2] Suatu keadaan $\mathbf{x}_{0}$ dikatakan terkontrol jika terdapat input $\mathbf{u}(k)$, $k \in \mathbb{Z}_{+}$, yang mentransfer keadaan $\mathbf{x}(k)$ dalam sistem (1.1.1) dari keadaan $\mathbf{x}(0)=\mathbf{x}_{0}$ kepada keadaan $\mathbf{0}$ dalam waktu berhingga $K$, yaitu $\mathbf{x}(K)=\mathbf{0}$.

Misalkan $\mathfrak{R}_{c}$ menyatakan himpunan keadaan terkontrol dalam waktu $K$, yang secara simbolik dapat ditulis.

$$
\mathfrak{R}_{c}=\left\{\mathbf{x} \in \mathbb{R}^{n} \mid \mathbf{x} \text { terkontrol dalam waktu } K\right\} .
$$

Definisi 4. [2] Sistem (1) dikatakan terkontrol jika setiap keadaan $\mathbf{x} \in \mathbb{R}^{n}$ adalah terkontrol.

Dari definisi keterkontrolan diperoleh bahwa keadaan $\mathbf{x}_{0}$ terkontrol jika $\mathbf{x}_{0}$ bisa ditransfer kepada keadaan $\mathbf{0}$ dalam waktu berhingga $K$ jika dan hanya jika

$$
-A^{K} \mathbf{x}_{0}=\mathcal{C}_{K} U_{K}
$$

akibatnya

$$
A^{K} \mathbf{x}_{0} \in \mathcal{R}\left(\mathcal{C}_{K}\right)
$$

\section{Hubungan antara Ketercapaian dan Keterkontrolan Sistem Linier Diskrit}

Lema 1. Jika $\mathbf{x} \in \mathcal{R}(\mathcal{C})$ maka $A \mathbf{x} \in \mathcal{R}(\mathcal{C})$; yaitu subruang tercapai $\mathfrak{R}_{r}=\mathcal{R}(\mathcal{C})$ adalah suatu subruang invarian pada $A$.

Teorema 2. Untuk sistem (1) dengan A singular,

(i) Jika keadaan $\mathbf{x}$ tercapai, maka keadaan $\mathbf{x}$ terkontrol.

(ii) $\mathfrak{R}_{r} \subseteq \mathfrak{R}_{c}$ 
(iii) Jika sistem tercapai, maka sistem tersebut juga terkontrol.

Selanjutnya, jika A nonsingular, maka hubungan pada (i) dan (iii) menjadi pernyataan jika dan hanya jika, sehingga keterkontrolan secara tidak langsung juga menyatakan ketercapaian dan hubungan pada (ii) menjadi suatu kesamaan yaitu $\mathfrak{R}_{r}=\mathfrak{R}_{c}$.

\section{Bukti.}

(i) Keadaan $\mathbf{x}$ tercapai, maka

$$
\mathbf{x} \text { tercapai } \Rightarrow \mathbf{x} \in \mathcal{R}(\mathcal{C}) \text {. }
$$

Berdasarkan Lema 3.1 berlaku

$$
A \mathrm{x} \in \mathcal{R}(\mathcal{C})
$$

Sehingga $A^{n} \mathbf{x} \in \mathcal{R}(\mathcal{C})$, yang menunjukkan bahwa keadaan $\mathbf{x}$ juga terkontrol.

(ii) Keadaan $\mathbf{x} \in \mathfrak{R}_{r}$ sebarang, akan ditunjukkan $\mathbf{x} \in \mathfrak{R}_{c}$.

$$
\begin{aligned}
\mathrm{x} \in \mathfrak{R}_{r} \Rightarrow & \mathrm{x} \text { tercapai dan } \mathrm{x} \in \mathbb{R}^{n} \\
& \Rightarrow \mathrm{x} \in \mathcal{R}(\mathcal{C}) \\
& \Rightarrow A \mathrm{x} \in \mathcal{R}(\mathcal{C}) \\
& \Rightarrow A^{n} \mathbf{x} \in \mathcal{R}(\mathcal{C}) \\
& \Rightarrow \mathrm{x} \in \mathfrak{R}_{c}
\end{aligned}
$$

Jadi, $\mathfrak{R}_{r} \subseteq \mathfrak{R}_{c}$.

(iii) Suatu sistem diskrit dikatakan tercapai jika setiap keadaan dari sistem tersebut adalah tercapai. Dari (i) kita ketahui bahwa jika suatu keadaan tercapai maka keadaan tersebut juga terkontrol. Jadi, apabila sistem tercapai maka sistem tersebut juga terkontrol.

\section{Ucapan Terima Kasih}

Penulis mengucapkan terima kasih kepada Bapak Dodi Devianto, Bapak Admi Nazra, Bapak Narwen, Bapak Muhafzan dan Bapak Effendi yang telah memberikan kritik dan saran sehingga makalah ini dapat diselesaikan dengan baik.

\section{Daftar Pustaka}

1. Antsaklis, Panos J. dan Anthony N. Michel. 2006. Linear Systems. Birkhuser. Boston.

2. Antsaklis, Panos J. dan Anthony N. Michel. 2007. A Linear Systems Primer. Birkhuser. Boston.

3. Heij, Christian. Ran, Andre dan Schagen, F. 2007. Introduction to mathematical Systems Theory.Birkhuser. Boston. 